\title{
Loss of Heterozygosity at Chromosome 16q Is a Negative Prognostic Factor in Korean Pediatric Patients with Favorable Histology Wilms Tumor: A Report of the Korean Pediatric Hematology Oncology Group (K-PHOG)
}

\author{
Jun Eun Park, MD, PhD ${ }^{1}$ \\ O Kyu Noh, MD, PhD² \\ Yonghee Lee, MD, $\mathrm{PhD}^{3}$ \\ Hyoung Soo Choi, MD, PhD ${ }^{4}$ \\ Jung Woo Han, MD, PhD ${ }^{5}$ \\ Seung Min Hahn, MD, PhD \\ Chuhl Joo Lyu, MD, PhD \\ Ji Won Lee, MD, $P h D^{6}$ \\ Keon Hee Yoo, MD, PhD ${ }^{6}$ \\ Hong Hoe Koo, MD, PhD 6 \\ Seon-Yong Jeong, $\mathrm{PhD}^{7}$ \\ Ki Woong Sung, MD, PhD ${ }^{6}$
}

Departments of ${ }^{1}$ Pediatrics, ${ }^{2}$ Radiation Oncology, and ${ }^{3}$ Pathology, Ajou University School of Medicine, Suwon, ${ }^{4}$ Department of Pediatrics, Seoul National University Bundang Hospital, Seongnam, ${ }^{5}$ Department of Pediatric Hematology and Oncology, Yonsei Cancer Center, Yonsei University Health System, Seoul, ${ }^{6}$ Department of Pediatrics, Samsung Medical Center, Sungkyunkwan University School of Medicine, Seoul, 'Department of Medical Genetics, Ajou University School of Medicine, Suwon, Korea

Correspondence: Ki Woong Sung, MD, PhD Department of Pediatrics, Samsung Medical Center, Sungkyunkwan University School of Medicine, 81 Irwon-ro, Gangnam-gu,

Seoul 06351, Korea

Tel: 82-2-3410-3529

Fax: 82-2-3410-0049

E-mail: kwsped@skku.edu

Co-correspondence: Seon-Yong Jeong, PhD Department of Medical Genetics,

Ajou University School of Medicine, 206 World cup-ro, Yeongtong-gu, Suwon 16499, Korea

Tel: 82-31-219-4520

Fax: 82-31-219-4521

E-mail: jeongsy@ajou.ac.kr

Received June 7, 2019

Accepted September 9, 2019

Published Online September 10, 2019

\section{Purpose}

Loss of heterozygosity ( $\mathrm{LOH}$ ) at chromosomes $1 p$ and $16 q$ is a poor prognostic factor in favorable histology Wilms tumor (FHWT). This study investigated the prevalence of LOH at $1 p$ and $16 q$ and evaluated its prognostic value in Korean children with FHWT.

\section{Materials and Methods}

We analyzed 101 FHWT patients who were diagnosed between 1996 and 2016 in Korean Society of Pediatric Hematology Oncology Group hospitals. Using paraffin-embedded kidney tissue samples sent from each center, we reviewed LOH at $1 p$ and $16 q$ in each patient and assessed the prognostic value of LOH status for clinical parameters affecting event-free survival (EFS).

\section{Results}

Of the 101 patients, 12 (11.9\%) experienced recurrence; the 3-year EFS was 87.6\%. LOH at $1 p$ or $16 q$ was detected in 19 patients (18.8\%), with five having LOH at both $1 q$ and $16 q$. The frequency of $\mathrm{LOH}$ at $1 p$ was higher among younger patients $(p=0.049)$, but there was no difference in $\mathrm{LOH}$ prevalence according to tumor stage. In the multivariate analysis, $\mathrm{LOH}$ at $16 q$ was a significant negative prognostic factor affecting EFS (3-year EFS, $73.7 \%$ vs. 91.1\%; hazard ratio, 3.95; $p=0.037)$, whereas $\mathrm{LOH}$ at $1 p$ was not $(p=0.786)$.

\section{Conclusion}

$\mathrm{LOH}$ at $16 \mathrm{q}$ was a significant negative prognostic factor affecting outcome in Korean pediatric FHWT patients. Due to the small sample size of this study, large-scale multicenter trials are warranted to investigate the prognostic value of $\mathrm{LOH}$ at $1 p$ and $16 q$ in Korean children with FHWT.
Key words

Wilms tumor, Loss of heterozygosity, 16q, 1p, Survival, Prognosis 


\section{Introduction}

Around 7\% of malignant neoplasms occur in the kidney; these include Wilms tumor (WT; also known as nephroblastoma), clear cell sarcoma of the kidney, malignant rhabdoid tumor, and renal cell carcinoma $[1,2]$. WT is the most common primary kidney tumor in children and is treated with a multimodal approach that consists of surgery, radiation therapy, and anticancer drugs [3]. Based on tumor stage and pathological findings of upfront nephrectomy, the National Wilms Tumor Study Group (NWTSG) recommends treating WT according to the risk of relapse [4]. In contrast, the International Society of Pediatric Oncology advocates upfront chemotherapy before nephrectomy, with the intensity of subsequent therapies adjusted according to tumor response [5]. Attempts to treat WT patients according to the risk of tumor recurrence using prognostic markers has led to improvement in outcome over the past 40 years, such that the long-term survival rate is now $90 \%$ [6].

Tumor suppressor genes contribute to tumorigenesis by disabling the function of both normal alleles of a gene $[7,8]$. Loss of heterozygosity ( $\mathrm{LOH}$ ) at a chromosomal locus comprising a tumor suppressor gene results in functional defects that can lead to pediatric WT [7,9]. It was recently reported that $\mathrm{LOH}$ at chromosome $1 \mathrm{p}$ and/or $16 \mathrm{q}$ is associated with high recurrence and mortality rates in WT patients. The National Wilms Tumor Study (NWTS)-5 reported that tumorspecific LOH at $1 p$ and $16 q$ was associated with a higher risk of relapse and death in favorable histology Wilms tumor (FHWT), and treatment intensity was increased in these patients [6].

However, different investigators have reported variable findings regarding the prognostic value of $\mathrm{LOH}$ at $1 \mathrm{p}$ and 16q [10-12]: some have shown that $\mathrm{LOH}$ at both loci predicts survival, while others have found that only one or the other affects prognosis [13]. These discrepancies could be due to several causes, not only differences in the study populations, but also differences in ethnic variation. The present study investigated the prognostic significance of $\mathrm{LOH}$ at $1 \mathrm{p}$ and $16 \mathrm{q}$ in a Korean pediatric FHWT cohort.

\section{Materials and Methods}

\section{Patients and treatment}

The study protocol was approved by the WT committee of the Korean Society of Pediatric Hematology Oncology Group (K-PHOG), which analyzed patient information and speci- mens from the four participating hospitals, each of which passed Institutional Review Board deliberation, filled out the case report form (CRF), and sent five-panel slides for each patient to the committee for retrospective review. All patints included in this study were diagnosed as FHWT between 1996 and 2016; examined by chest X-ray, abdominal sonography, computed tomography, or magnetic resonance imaging; staged according to the NWTSG staging system; and treated according to National Wilms' Tumor Study 4 (NWTS4) guidelines [6]. One institution modified the NWTS-4 treatment guideline; initial fine needle biopsy and delayed nephrectomy was done at 6 to 9 weeks if the largest diameter of the tumor is greater than $8 \mathrm{~cm}$ (modified NWTS). The CRF included data on the patient's age, sex, histological findings, staging at the time of diagnosis, surgery, radiation, chemotherapy, relapse, and survival.

Upfront nephrectomy was initially recommended for all patients. However, chemotherapy was given prior to nephrectomy if the tumor was deemed unresectable by the surgeon or if the surgery was life-threatening, the tumor thrombus extended into the inferior vena cava above the level of the hepatic veins, or the disease was bilateral by Doppler sonography. Stage I-II patients received two drugs including vincristine and actinomycin D for 18 weeks without radiotherapy, and stage III-IV patients were treated with a threedrug regimen consisting of vincristine, actinomycin, and doxorubicin for 24 weeks in addition to receiving radiotherapy. Stage V patients were treated with nephron-sparing surgery and chemotherapy or delayed nephrectomy after preoperative chemotherapy and then postoperative chemotherapy.

\section{Histopathological examination and DNA extraction for microsatellite analysis}

Paraffin-embedded kidney specimens containing normal and tumor tissues that were cut into $5-\mu \mathrm{m}$ sections and mounted on glass slides (five per patient) were sent from participating institutions to that of the principal investigator. Pathological diagnoses were reviewed at a central location and tumor cells were microdissected under a microscope from hematoxylin and eosin-stained sections. DNA was extracted from tumor and non-tumor sections for microsatellite analysis according to standard procedures. Two tissue sections from each case were transferred using a disposable razor blade to $900 \mu \mathrm{L}$ of xylene in a $1.5-\mathrm{mL}$ microcentrifuge tube. Equal volumes of $100 \%$ and $70 \%$ ethanol were added and the samples were pelleted (10 minutes in a microcentrifuge), dried at $56^{\circ} \mathrm{C}$, and incubated overnight in cell lysis buffer (cat. No. 1045723, Qiagen, Valencia, CA) with $1.5 \mu \mathrm{L}$ of proteinase $\mathrm{K}(41 \mu \mathrm{g} / \mathrm{mg})$. The proteinase $\mathrm{K}$ was inactivated by heating the samples at $56^{\circ} \mathrm{C}$ for $30-60$ minutes; 100 


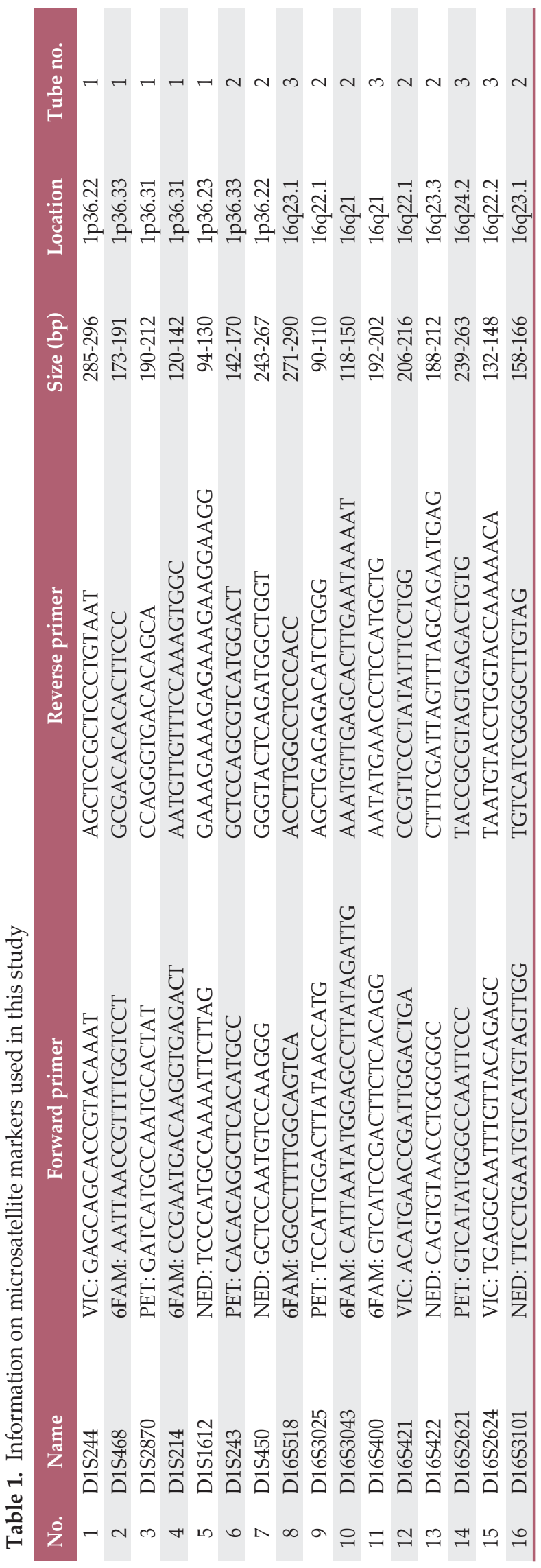

$\mu \mathrm{L}$ of protein precipitation solution (cat. No. 1045701, Qiagen) was added to each sample, followed by centrifugation for 5 minutes. The supernatant was removed and isopropanol was added to precipitate the DNA, which was washed with $70 \%$ ethanol and transferred to a new $1.5-\mathrm{mL}$ tube.

\section{Detection of LOH at $1 p$ and $16 q$}

To detect $\mathrm{LOH}$ at $1 \mathrm{p}$ and $16 \mathrm{q}, 16$ polymorphic microsatellite markers were selected based on a previous study [6]. Forward primers were labeled with four different fluorescent dyes (VIC, 6FAM, PET, or NED) (Table 1). Polymerase chain reaction (PCR) amplification was performed on tumor and normal tissue samples in triplicate using the Qiagen Multiplex PCR Plus Kit (Hilden, Germany) under the following conditions: $95^{\circ} \mathrm{C}$ for 10 minutes; five cycles of $95^{\circ} \mathrm{C}$ for $20 \mathrm{sec}-$ onds, $60^{\circ} \mathrm{C}$ for 90 seconds $\left(-1^{\circ} \mathrm{C}\right.$ in each cycle), and $72^{\circ} \mathrm{C}$ for 1 minute; 30 cycles of $95^{\circ} \mathrm{C}$ for 20 seconds, $55^{\circ} \mathrm{C}$ for 90 seconds, and $72^{\circ} \mathrm{C}$ for 1 minute; and $60^{\circ} \mathrm{C}$ for 30 minutes. PCR products were examined using a 3500xL Dx Genetic Analyzer (Thermo Fisher Scientific, Waltham, MA) and LOH was detected using GeneMapper v.4.1 software (Thermo Fisher Scientific) according to the manufacturer's instructions.

\section{Statistical analysis}

Event-free survival (EFS) refers to the time from diagnosis to the first occurrence of progression, relapse after response or death from any cause. Overall survival (OS) was defined as the time from diagnosis to the day of death or last follow up. EFS and OS were calculated with the Kaplan-Meier method, and the log-rank test and the Cox proportional hazards model were used for uni- and multivariate analyses, respectively. The chi-square test was used to compare the contingency tables. Two-sided p-values $<0.05$ were considered statistically significant.

\section{Ethical statement}

This study was performed in accordance with the ethical guidelines of the "World Medical Association Declaration of Helsinki-Ethical Principles for Medical Research Involving Human Subjects." This study was approved by the Institutional Review Board of participating institutions and Ajou University Hospital (IRB No. AJIRB-BMR-OBS-16-143). Written informed consent was waived from the IRB. 
Table 2. Characteristics of patients with favorable histology Wilms tumors

\begin{tabular}{|c|c|}
\hline Patient characteristic & $\begin{array}{l}\text { No. of patients }(\%) \\
(n=101)\end{array}$ \\
\hline \multicolumn{2}{|l|}{ Age at diagnosis (yr) } \\
\hline Mean (range) & $2.8(0.3-10.4)$ \\
\hline$<2$ & $52(51.5)$ \\
\hline $2-10$ & $23(22.8)$ \\
\hline$>10$ & $26(25.7)$ \\
\hline \multicolumn{2}{|l|}{ Sex } \\
\hline Male & $48(47.5)$ \\
\hline Female & $53(52.5)$ \\
\hline \multicolumn{2}{|l|}{ Primary tumor site } \\
\hline Right & $43(42.6)$ \\
\hline Left & $52(51.5)$ \\
\hline Both & $6(5.9)$ \\
\hline \multicolumn{2}{|l|}{ Stage } \\
\hline I & $25(24.8)$ \\
\hline II & $15(14.9)$ \\
\hline III & $43(42.6)$ \\
\hline IV & $12(11.9)$ \\
\hline $\mathrm{V}$ & $6(5.9)$ \\
\hline \multicolumn{2}{|l|}{ Treatment strategy } \\
\hline NWTS-4 & $53(52.5)$ \\
\hline Modified NWTS-4 & $48(47.5)$ \\
\hline \multicolumn{2}{|l|}{ Nephrectomy } \\
\hline Upfront & $54(53.4)$ \\
\hline Delayed & $47(46.5)$ \\
\hline Metastasis to lung at diagnosis & $11(10.9)$ \\
\hline \multicolumn{2}{|l|}{ Loss of heterozygosity for $1 p / 16 q$} \\
\hline 1p only & $14(13.9)$ \\
\hline 16q only & $14(13.9)$ \\
\hline Both $1 p$ and $16 q$ & $5(5.0)$ \\
\hline
\end{tabular}

NWTS-4, National Wilms' Tumor Study 4.

\section{Results}

A total of 101 FHWT patients were enrolled in the study. The median age was 2.8 years (range, 0.3 to 10.4 years). The male-to-female ratio (48:53) was 1.04. The characteristics of the study population are summarized in Table 2 . Among the patients, $43(42.6 \%)$ and $52(51.5 \%)$ had tumors in the right and left kidneys, respectively, whereas six $(5.9 \%)$ had tumors in both kidneys. Eleven patients showed distant metastasis to the lung. Upfront nephrectomy was performed in 54 patients and delayed nephrectomy in 47; the latter was performed after preoperative chemotherapy since 37 cases were deemed inoperable by the surgeon, with six cases of bilateral disease and four in which the tumor thrombus extended into

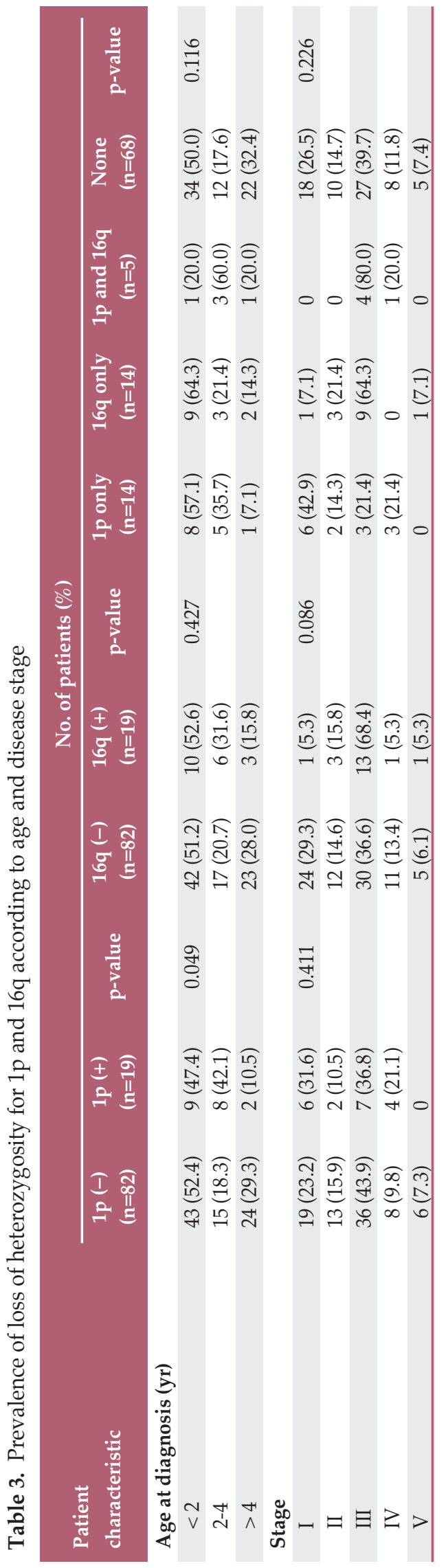


the inferior vena cava above the level of the hepatic veins.

Forty patients received radiotherapy.

The status of $\mathrm{LOH}$ at $1 \mathrm{p}$ and $16 \mathrm{q}$ in the patients is shown in Table 3. There were 19 patients $(18.8 \%)$ with $\mathrm{LOH}$ at $1 \mathrm{p}$ and $16 \mathrm{q}$ respectively, including five exhibiting $\mathrm{LOH}$ at both loci. The frequency of $\mathrm{LOH}$ at $1 \mathrm{p}$ was higher among younger patients $(p=0.049$ ), especially those under 4 years of age. There was no difference in $\mathrm{LOH}$ prevalence according to tumor stage (Table 3).

Among the 101 patients, there were 12 recurrences and two deaths. The 3-year OS and EFS of all patients were $98.0 \%$ and $87.6 \%$, respectively. The 3-year EFS rate was $89.5 \%$ in patients with and $87.2 \%$ in those without $\mathrm{LOH}$ at $1 \mathrm{p}(\mathrm{p}=0.798$ [log-rank test]) (Fig. 1A). The 3-year EFS rate was lower in patients with $\mathrm{LOH}$ than in those without $\mathrm{LOH}$ at $16 \mathrm{q}(73.7 \%$ vs. $91.1 \%, p=0.047$ [log-rank test]) (Fig. 1B). Patients with $\mathrm{LOH}$ at both $1 \mathrm{p}$ and $16 \mathrm{q}$ did not show a lower EFS rate than those in the other groups (Fig. 1C).

A multivariate analysis showed that $\mathrm{LOH}$ at $16 \mathrm{q}$ was a significant negative prognostic factor for EFS (hazard ratio, 3.95; $\mathrm{p}=0.037$ ), which was not true of $\mathrm{LOH}$ at $1 \mathrm{p}$ (hazard ratio, 0.83; $\mathrm{p}=0.817$ ) (Table 4).

\section{Discussion}

There has been significant progress in the treatment of FHWT over the past 30 years, and the survival rate is now about $90 \%$ [14]. This excellent outcome is the result of a multimodal approach that combines surgery, chemotherapy, and radiation therapy according to tumor stage and histology. Additionally, tumors at high risk of recurrence are treated more aggressively than those at low risk, such that overtreatment can be avoided in the latter cases [15]. Recently, efforts have been made to identify new molecular markers that can be used to predict tumor recurrence by stratifying high- and low-risk patients, which can ultimately prolong survival by reducing long-term treatment sequelae $[7,9]$. There have been many reports of $\mathrm{LOH}$ in relation to the risk of recurrence of $\mathrm{WT}$, for instance at $1 p, 11 q, 16 q$, and $22 q[10,13,16]$. Of these, $\mathrm{LOH}$ at $1 \mathrm{p}$ and $\mathrm{LOH} 16 \mathrm{q}$ are the most widely investigated and were the focus of the present work.

In our study, 19 patients each out of $101(18.9 \%)$ had LOH at $1 \mathrm{p}$ and 16q. We compared these rates to the ones reported in other studies (Table 5). Of the 232 WT patients enrolled in NWTS-3 and $-4,21$ patients $(12 \%)$ had $\mathrm{LOH}$ at $1 \mathrm{p}$ and 35 $(17 \%)$ at 16q [10]. In NWTS-5, 196 out of 1,727 FHWT patients $(11.3 \%)$ had LOH at $1 p$ and $301(17.4 \%)$ had LOH at 16q [4]. Of the 426 FHWT patients enrolled in the UKW 1-3 trials, the prevalence of $\mathrm{LOH}$ at $1 \mathrm{p}$ and $16 \mathrm{q}$ was $10.3 \%$ and $17.4 \%$, res-

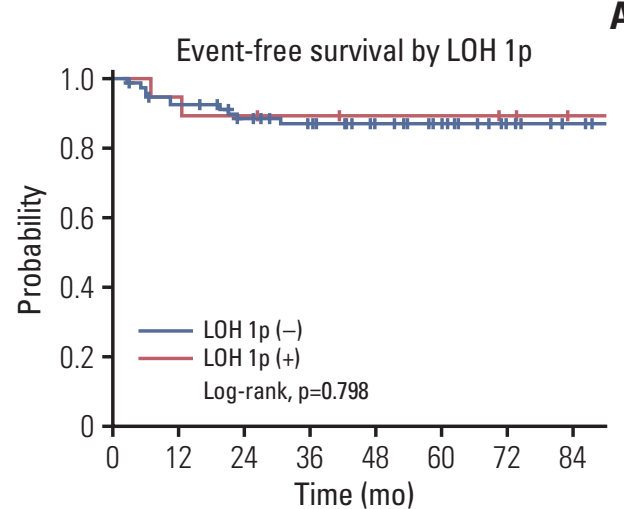

A

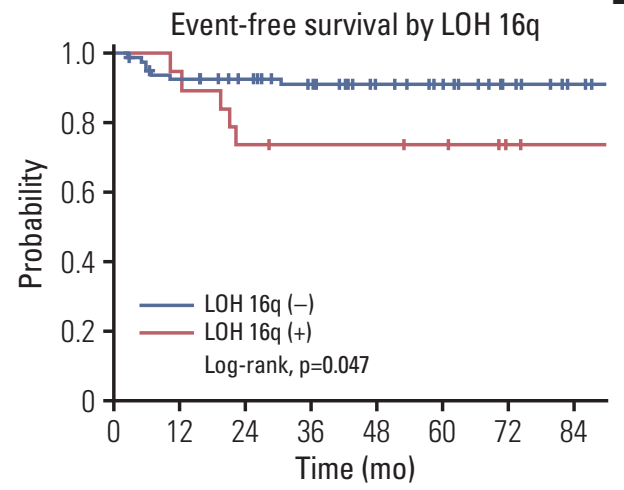

B

Event-free survival by LOH $1 p$ and $16 q$

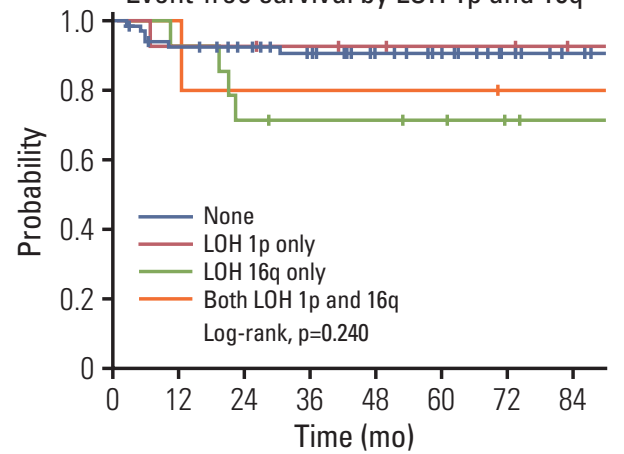

Fig. 1. Event-free survival rates according to loss of heterozygosity ( $\mathrm{LOH})$ at $1 \mathrm{p}(\mathrm{A})$ and $16 \mathrm{q}(\mathrm{B})$ and four groups classified as 1p only, 16q only, none, and both (C).

pectively [11]; among the 125 patients who participated in the AIEOP-TW-2003 trial, the rates were $19 \%$ and 15\%, respectively [13]; and in an Egyptian FHWT cohort $(\mathrm{n}=100)$, the rates were $16 \%$ and $25 \%$, respectively [12]. Thus, with the exception of one report [12], the prevalence of $\mathrm{LOH}$ at $1 \mathrm{p}$ and $16 \mathrm{q}$ is about $10 \%-19 \%$ and $14 \%-20 \%$, respectively, whereas the proportion of patients with both alterations is between 
Table 4. Event-free survival rates and hazard ratio according to age, stage, and $\mathrm{LOH}$ at $1 \mathrm{p}$ and 16q status (multivariate analysis)

\begin{tabular}{|c|c|c|c|}
\hline & $\begin{array}{c}\text { Event-free survival } \\
\text { (3-year) }(\%)\end{array}$ & $\begin{array}{c}\text { Hazard ratio } \\
\qquad(95 \% \mathrm{CI})\end{array}$ & p-value \\
\hline \multicolumn{4}{|l|}{ Age (yr) } \\
\hline$<2$ & 90.0 & 1 & \\
\hline $2-4$ & 91.3 & $0.84(0.15-4.53)$ & 0.835 \\
\hline$>4$ & 79.6 & $2.40(0.67-8.55)$ & 0.176 \\
\hline \multicolumn{4}{|l|}{ Stage } \\
\hline I-II & 90.6 & 1 & \\
\hline III-V & 84.5 & $1.11(0.24-5.15)$ & 0.893 \\
\hline \multicolumn{4}{|l|}{ Treatment strategy } \\
\hline NWTS-4 & 88.2 & 1 & \\
\hline Modified NWTS-4 & 86.9 & $0.73(0.15-3.51)$ & 0.695 \\
\hline \multicolumn{4}{|l|}{ LOH 1p } \\
\hline Absent & 82.7 & 1 & \\
\hline Present & 89.5 & $0.83(0.17-4.01)$ & 0.817 \\
\hline \multicolumn{4}{|l|}{ LOH 16q } \\
\hline Absent & 91.1 & 1 & \\
\hline Present & 73.7 & $3.95(1.08-14.39)$ & 0.037 \\
\hline
\end{tabular}

LOH, loss of heterozygosity; CI, confidence interval; NWTS-4, National Wilms' Tumor Study 4.

Table 5. Summary of previous studies on the prevalence and hazard ratio of relapse risk associated with $\mathrm{LOH}$ at $1 \mathrm{p}$ or / and $16 \mathrm{q}$

\begin{tabular}{|c|c|c|c|c|c|}
\hline Study & $\begin{array}{l}\text { Source of } \\
\text { study }\end{array}$ & $\begin{array}{c}\text { No. of } \\
\text { patients }\end{array}$ & $\begin{array}{l}\text { Prevalence of LOH } \\
\text { 1p/16q/both }(\%)\end{array}$ & HR or RR & p-value \\
\hline Grundy et al. [10] & NWTS-3,4 & 232 & $12 / 17 / 4$ & RR 3.3 for $16 q$ vs. none & 0.01 \\
\hline Grundy et al. [6] & NWTS-5 & 1,727 & $11.3 / 17.4 / 4.6$ & $\begin{array}{l}\text { Stage I-II, RR } 2.9 \text { (95\% CI, 1.51-5.49) for } \\
\text { both vs. none, 1p only, and 16q only } \\
\text { stage III-IV, RR } 2.4 \text { (95\% CI, 1.20-4.82) for } \\
\text { both vs. none, 1p only, and 16q only }\end{array}$ & 0.001 \\
\hline Messahel et al. [11] & UKW 1-3 & 426 & $10.3 / 17.4 / 2.6$ & HR 2.64 (95\% CI, 1.47-4.92) for $16 q$ vs. none & $<0.001$ \\
\hline Spreafico et al. [13] & AIEOP-TW-2003 & 125 & $19 / 14 / 4$ & HR 4.1 (95\% CI, $1.60-10.8)$ for $1 p$ vs. none & 0.0009 \\
\hline Fawzy et al. [12] & $\begin{array}{l}\text { National Cancer } \\
\text { Institute, Egypt }\end{array}$ & 100 & $26 / 25 / 12$ & $\begin{array}{l}53.8 \% \text { a) }, 50 \% \text { for } 16 q \text { only, } \\
\text { and both vs. } 1 \text { p only }\end{array}$ & 0.007 \\
\hline This study & K-PHOG & 101 & $18.8 / 18.8 / 5$ & HR 3.84 (95\% CI, 1.31-13.0) for $16 \mathrm{q}$ vs. none & 0.031 \\
\hline
\end{tabular}

LOH, loss of heterozygosity; HR, hazard ratio; RR, relative risk (Cox model for relapse or events for specific LOH); NWTS-

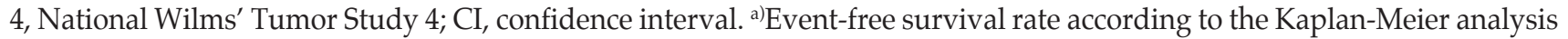
and compared with the log-rank test.

$2.6 \%$ and $5 \%$ (i.e., $4.6 \%$ [4], 2.6\% [11], and $4 \%$ [13]). Five out of 101 patients in our study had LOH at both 1p and 16q, which is comparable to the rates in these other studies.

The frequencies of $\mathrm{LOH}$ at $1 \mathrm{p}$ and $16 \mathrm{q}$ are higher among FHWT patients over 4 years old [4], and lower in patients younger than 2 years old [12]. One study found that the frequency $\mathrm{LOH}$ at $1 \mathrm{p}$ but not at 16q increased after 4 years of age [11]. Others have shown a low prevalence of $\mathrm{LOH}$ at $1 \mathrm{p}$ but not at $16 q$ in patients under 2 years old [13]. In our study, the rate of $\mathrm{LOH}$ at $1 \mathrm{p}$ was higher among younger FHWT patients $(\mathrm{p}=0.045)$, especially in those under 4 years old (Table 3). These same age-group differences in the frequency of LOHs appearing among the reports may represent interracial biological differences in WTs. It was reported that the 
frequency of $\mathrm{LOH}$ at $1 \mathrm{p}$ or $16 \mathrm{q}$ increases with tumor stage [12]; however, in most other studies $[6,11,13]$ including ours, there was no association between the frequency of these alterations and tumor stage.

Several studies have investigated whether $\mathrm{LOH}$ at $1 \mathrm{p}$ and / or 16q can predict FHWT recurrence and patient survival (Table 5). NWTS-5 is the largest of these studies to date; it was prospective in nature and used stage-specific treatment, and showed that $\mathrm{LOH}$ at both $1 \mathrm{p}$ and $16 \mathrm{q}$ loci was associated with worse prognosis [4]. In NWTS-3 and -4 , which preceded NWTS-5, LOH at $16 \mathrm{q}$ was associated with 3.3- and 12-fold higher rates of relapse and mortality, but $\mathrm{LOH}$ at $1 \mathrm{p}$ tended to increase recurrence and mortality rates without statistically significant $[2,10]$. In this study, it is thought that the preceding NWTS-3,4 study was a statistical difference caused by the smaller sample sizes than the NWTS-5 study.

However, it is thought that there would be another reason for different results in determining $\mathrm{LOH}(\mathrm{s})$ at $1 \mathrm{q}$ and / or 16q as prognostic factor(s). In a study of 125 children with FHWT treated with the AIEOP-TW-2003 protocol which was conducted in Italy from 2003 to 2008, LOH at $1 \mathrm{p}$ was associated with worse disease-free survival [13]. Meanwhile, in the UKW 1-3 trials conducted in the United Kingdom with a relatively large number of subjects, 426 FHWT patients, $\mathrm{LOH}$ at $16 q$ but not at $1 p$ was also associated with a higher risk of relapse and death [11]. In a study of Egyptian FHWT patients, $\mathrm{LOH}$ at $16 \mathrm{q}$ alone or in combination with $\mathrm{LOH}$ at $1 \mathrm{p}$ had a higher recurrence rate and lower 3-year EFS [12]. It can be inferred that genetic variability of the WT may have racial differences to produce different outcomes for each country that conducted the study. In our study, EFS was lower in patients with $\mathrm{LOH}$ at $1 \mathrm{p}$ only or at both $1 \mathrm{p}$ and $16 \mathrm{q}$ compared with those with neither alteration; this was not statistically significant, possibly due to our small sample size. Nonetheless, our results show that only $\mathrm{LOH} 16 \mathrm{q}$ negatively affects prognosis, which is consistent with previous findings [4,1012]. This result is thought to reflect racial differences, as stated earlier in the study conducted in United Kingdom, Egypt, and Italy.
Only cases of LOH at both 1p and 16q in FHWT stages I-IV are stratified into poor prognosis groups and receive additional intensive chemotherapy, although both types of alteration show a low prevalence of 4\% [6]. Thus, the absolute number of patients who would benefit from clinical decisions made based on the identification of LOH may be relatively small if they were classified as high risk and given intensive chemotherapy [13]. In our study, five patients among the 19 with $\mathrm{LOH}$ at $16 \mathrm{q}$ experienced recurrence; assuming that this group be received more aggressive treatment in the future study, the remaining 14 will be likely overtreated. Therefore, it is important that patients are stratified with higher statistical power and treated in combination with other risk factors rather than classified as a recurrent risk group based solely on detection of $\mathrm{LOH}$ at 16q [9].

The limitation of our study is that although it was a nationwide study conducted by K-PHOG the sample size was relatively small, this is especially true for $\mathrm{LOH}$ at $1 \mathrm{p}$ that is statistically insignificant. Second, the study was retrospective and therefore did not have a uniform staging system and treatment strategy. Therefore, the next study needs a prospective study with a uniformed staging system and treatment strategy.

This study is meaningful in that it is the first to identify $\mathrm{LOH}$ at $16 \mathrm{q}$ as a significant negative prognostic factor affecting outcome in Korean pediatric FHWT patients. However, this study is limited to its small sample size, large-scale multicenter trials are warranted to investigate the prognostic value of $\mathrm{LOH}$ at $1 \mathrm{p}$ and 16q in Korean children with FHWT.

\section{Conflicts of Interest}

Conflict of interest relevant to this article was not reported.

\section{Acknowledgments}

This study was supported by a grant from Ajou University Medical Center (grant No. M-2015-C0460-00110).

\section{References}

1. Bu Q, He H, Fan D, Lyu J, Pan Z, You H. Association between loss of heterozygosity of chromosome $16 \mathrm{q}$ and survival in Wilms' tumor: a meta-analysis. Pathol Res Pract. 2018;214: 1772-7.

2. Kim DH, Son MH, Lee SH, Yoo KH, Sung KW, Koo HH, et al. Effect of preoperative chemotherapy on outcome of Wilms tumor. Clin Pediatr Hematol Oncol. 2011;18:103-8.
3. Green DM. The evolution of treatment for Wilms tumor. J Pediatr Surg. 2013;48:14-9.

4. Fernandez CV, Mullen EA, Chi YY, Ehrlich PF, Perlman EJ, Kalapurakal JA, et al. Outcome and prognostic factors in stage III favorable-histology Wilms tumor: a report from the Children's Oncology Group Study AREN0532. J Clin Oncol. 2018;36:254-61. 
5. Dome JS, Perlman EJ, Graf N. Risk stratification for Wilms tumor: current approach and future directions. Am Soc Clin Oncol Educ Book. 2014:215-23.

6. Grundy PE, Breslow NE, Li S, Perlman E, Beckwith JB, Ritchey $\mathrm{ML}$, et al. Loss of heterozygosity for chromosomes $1 p$ and $16 \mathrm{q}$ is an adverse prognostic factor in favorable-histology Wilms tumor: a report from the National Wilms Tumor Study Group. J Clin Oncol. 2005;23:7312-21.

7. Skotnicka-Klonowicz G, Rieske P, Bartkowiak J, Szymik-Kantorowicz S, Daszkiewicz P, Debiec-Rychter M. 16q heterozygosity loss in Wilms' tumour in children and its clinical importance. Eur J Surg Oncol. 2000;26:61-6.

8. Loke BN, Wong MK, Tawng KD, Kuick CH, Jain S, Lian D, et al. Clinical, pathological and loss of heterozygosity differences in Wilms tumors between Asian and non-Asian children. Int J Cancer. 2019;144:1234-42.

9. Cone EB, Dalton SS, Van Noord M, Tracy ET, Rice HE, Routh JC. Biomarkers for Wilms tumor: a systematic review. J Urol. 2016;196:1530-5.

10. Grundy PE, Telzerow PE, Breslow N, Moksness J, Huff V, Paterson MC. Loss of heterozygosity for chromosomes $16 \mathrm{q}$ and $1 \mathrm{p}$ in Wilms' tumors predicts an adverse outcome. Cancer Res. 1994;54:2331-3.

11. Messahel B, Williams R, Ridolfi A, A'hern R, Warren W, Tinworth $\mathrm{L}$, et al. Allele loss at $16 \mathrm{q}$ defines poorer prognosis Wilms tumour irrespective of treatment approach in the
UKW1-3 clinical trials: a Children's Cancer and Leukaemia Group (CCLG) Study. Eur J Cancer. 2009;45:819-26.

12. Fawzy M, Bahanassy A, Samir A, Hafez H. Profiling loss of heterozygosity patterns in a cohort of favorable histology nephroblastoma Egyptian patients: what is consistent with the rest of the world. Pediatr Hematol Oncol. 2015;32:548-56.

13. Spreafico F, Gamba B, Mariani L, Collini P, D'Angelo P, Pession A, et al. Loss of heterozygosity analysis at different chromosome regions in Wilms tumor confirms 1p allelic loss as a marker of worse prognosis: a study from the Italian Association of Pediatric Hematology and Oncology. J Urol. 2013;189: 260-6.

14. Green DM, Breslow NE, Beckwith JB, Finklestein JZ, Grundy $\mathrm{P}$, Thomas PR, et al. Effect of duration of treatment on treatment outcome and cost of treatment for Wilms' tumor: a report from the National Wilms' Tumor Study Group. J Clin Oncol. 1998;16:3744-51.

15. Green DM, Breslow NE, Beckwith JB, Finklestein JZ, Grundy PE, Thomas PR, et al. Comparison between single-dose and divided-dose administration of dactinomycin and doxorubicin for patients with Wilms' tumor: a report from the National Wilms' Tumor Study Group. J Clin Oncol. 1998;16:237-45.

16. Dix DB, Seibel NL, Chi YY, Khanna G, Gratias E, Anderson JR, et al. Treatment of stage IV favorable histology Wilms tumor with lung metastases: a report from the Children's Oncology Group AREN0533 Study. J Clin Oncol. 2018;36:1564-70. 